\title{
Epidemiological surveillance of suicides and attempted suicides in Aquitaine, south-west France, using an original computer network of Sentinel General Practitioners.
}

\author{
SYLVIE MAURICE, ${ }^{1}$ XAVIER POMMEREAU, ${ }^{2}$ SOPHIE PUEYO, ${ }^{1}$ CLAUDE \\ TOULOUSE, ${ }^{1}$ BRUNO TILLY, ${ }^{1}$ FRANÇOIS DABIS, ${ }^{1}$ BERTRAND GARROS, ${ }^{3}$ AND \\ ROGER SALAMON. ${ }^{1}$

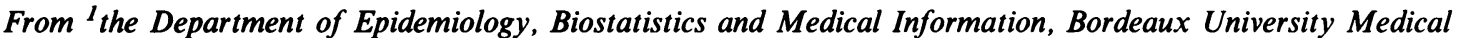 \\ Centre, France; ${ }^{2}$ the Medical Intensive Care Unit, Bordeaux Pellegrin Hospital, France; and ${ }^{3}$ the Observatoire \\ Régional de Santé d'Aquitaine, Bordeaux, France.
}

ABSTRACT To improve the epidemiological study of suicide and attempted suicides in Aquitaine, France, we developed a comprehensive surveillance system based on the input of Sentinel General Practitioners (SGPs). From October 1986 to May 1988, for each case of suicide or attempted suicide, the SGPs reported epidemiological data to our system through a computer network of personal home terminals (Minitels). Data included age, sex, method and result of attempt and antecedents. In ank analysis of the relationship between the suicidal method, antecedents and results of suicidal act, the principal findings were a high rate of antecedents of suicide attempts by drug overdoses, hangings and drownings; and no antecedents for attempts by the use of firearms. This may show that the increasing accessibility of firearms is making it more likely that impulsive suicide attempts will be lethal.

The epidemiological approach to the study of suicides and attempted suicides can be improved by a comprehensive surveillance system, surveillance being defined by Langmuir ${ }^{1}$ as a "continued watchfulness over the distribution and trends of incidence through the systematic collection, consolidation and evaluation of morbidity and mortality reports and other relevant data."

The sources of information for the surveillance of suicides and attempted suicides include a large number of professionals, volunteers, and institutions. Among health professionals concerned by this problem, General Practitioners (GPs) are the most likely to uncover suicidal cases and provide comprehensive data.

With this in mind, we included suicides and attempted suicides in the list of selected themes of our new regional epidemiological surveillance system which is based on the input of Sentinel General Practitioners (SGPs). The programme, which also includes surveillance of communicable diseases such as viral hepatitis, measles, acute diarrhoea, and sexually transmitted diseases, was initiated in October 1986 in the Aquitaine region of France, the third largest by area, comprising 2720000 inhabitants. $^{2}$ Our surveillance network was made possible by the French Telecommunications Company's ambitious home terminal (Minitel) distribution and promotion campaign, which enabled the installation of national and regional computer networks in France for the surveillance of communicable diseases. ${ }^{3}$

\section{Methods}

Our computer network gathered information from a group of $130 \mathrm{SGPs,}$ a representative sample which made up $5 \%$ of the regional GP population. The network was managed by the Department of Medical Information, at the Bordeaux University Medical Centre, with the assistance of specialists for each theme considered.

Each General Practitioner had a home terminal (Minitel) at his/her disposal, and could communicate data to the network 24 hours a day, 7 days a week. A minimum of one weekly contact to the network was requested of participants, even in the absence of any new case to report. Minitels have special modems incorporated which function under the French Videotex-Teletel norm. The data were transmitted 
through these terminals, by standard telephone lines, to a host minicomputer (6.74 BULL) located in the Bordeaux University Medical Centre.

The General Practitioner reported the epidemiological data for each suicide or attempted suicide for which he/she was the first practitioner to provide medical care. Relevant data included: age, sex, method of suicidal act, immediate results, suicide attempts in the previous year, and whether there were medical consultations during the month prior to the suicidal act.

\section{Results}

During the 20 months of surveillance (October 1986 to May 1988), data were gathered on 42 suicide completers and 253 suicide attempters.

The distribution of the total sample according to age and sex shows a ratio of two women to one man (198:97). The mean age was 41 years, with no significant difference between men and women.

Drug overdose was the principal method of suicide for both men and women $(54.6 \%$ and $80.3 \%$ respectively). The second most common method used differed for men and women: $17.5 \%$ of the men preferred firearms and $12.4 \%$ preferred hanging, while $9 \cdot 1 \%$ of women preferred cutting.

The immediate result of the suicidal act was different for men and women: $27.8 \%$ of suicidal males and $7.6 \%$ of suicidal females were found dead. Lethality for the total sample was $14.2 \%$, and $84.3 \%$ of males and $77 \cdot 1 \%$ of females were referred to a hospital. The discrepancy in outcomes reflects the difference in lethality of the methods used: from $0.5 \%$ for drug overdoses, to $58.3 \%$ for drownings, $77.8 \%$ for firearms, and $\mathbf{8 4 . 2 \%}$ for hangings. These last three methods were responsible for nearly 9 out of 10 completed suicides $(88 \%)$. Concerning attempted suicides in the previous year, a difference was noted in relation to suicidal method: among the "parasuicides", antecedents were found in $34.4 \%$ of drug overdoses and $36 \%$ of cuttings; among the highly lethal methods, antecedents were found in $31.6 \%$ of hangings and $25 \%$ of drownings; in contrast, firearm users in this sample had no suicidal antecedents.

Among completers and attempters, we observed a large proportion who sought medical consultation during the month prior to the suicidal act: $69 \%$ and $68 \%$ respectively. The majority $(80.8 \%)$ of these consultations were motivated, in the opinion of the SGP, by "psychological" problems, either exclusively or along with physical complaints. The motives for medical consultation in the month preceding the suicidal act will be analysed in a complementary study.

\section{Discussion}

In this 20 month period, the Minitel surveillance network system proved both its technical feasibility and its acceptability to sentinel GPs as an information transmitting medium.

The reliability of our findings was established by extrapolating the data, using a Poisson model, and comparing the results to pre-established findings from other sources. Patient's age, sex, and suicidal method were compatible with data collected from regional hospitals, ${ }^{4}$ and the suicidal methods found through our network corresponded to the methods documented for France as a whole. ${ }^{5}$

The high rates of suicide attempts in the previous year that we observed for "parasuicides" $(34.4 \%$ for drug overdoses and $36 \%$ for cuttings) are classic results. ${ }^{5}$ But similar rates are observed for hangings and drownings, which, as Pommereau and Penouil ${ }^{6}$ also observed in the case of jumpings, contradicts the commonly held belief that those who use these violent methods have fewer suicidal antecedents. However, firearm users in our findings had no suicidal antecedents. As Monk pointed out, ${ }^{7}$ the availability of a particular method of suicide (as a primary factor in suicide completion) has, since Boor ${ }^{8}$ and Farmer, received more attention than the method itself. Several studies have shown that, in the United States, there has been a large increase in the number of firearms available; correspondingly, nearly two fifths of suicidal females used firearms to commit suicide in 1980 , compared with one fifth in 1950 . Over the same period of time, the percentage of male suicides using firearms increased from $50 \%$ to $63 \% .^{1112}$ There is as yet no direct evidence that the increase in availability of firearms has indeed increased the number of suicides in the USA, but a number of studies strongly suggest such a connection. The strictness of gun control laws existing in various states in negatively correlated with their suicide rates, ${ }^{13-15}$ while the proportion of households with firearms is positively correlated to the suicide rates. ${ }^{16}$ Similar studies have yet to be carried out in France, where gun control laws allow only the possession of hunting guns. However in Aquitaine, the number of hunting licences has reached 207800 (21\% of the active population). Our findings support Farmer's hypothesis ${ }^{10}$ that the availability of a means of suicide may be important when the suicidal act is impulsive. It follows that ready access to usually lethal means of suicide, such as firearms, would increase suicides of an impulsive nature, especially among men, with no or few suicidal antecedents, as indicated in our results. This is probably one of the most important facts to consider in suicide prevention.

\section{Conclusion}

This kind of surveillance could improve the epidemiological approach to the phenomenon of suicide in our religion. Our data are useful in 
completing data on suicidal mortality and morbidity gathered from other sources: indeed, data on completed suicides are available elsewhere because of systematic recording by practitioners on death certificates. However, no such record is kept of attempted suicides; and most of the existing studies have been carried out by hospitals, to which, according to our results, less than $75 \%$ of the suicide attempters are referred by GPs.

Our network has also enabled us to study suicidal acts more thoroughly. For example, a case-control study on factors predictive of suicide attempts is being carried out currently. For each case noted, additional information was requested of the GPs to constitute a control sample based upon sex, age, and whether or not the patient was known by the GP. Three control patients were requested of the practitioner for each suicide completer or attempter. Data are now being analysed.

Finally, our study on suicide has uncovered a strong desire among General Practitioners to see more research and education done on this subject: they showed a high level of interest in the monthly reports of our results; they contributed to the analysis of the data; and, astounded by the high level of medical consultation preceding suicide attempts, they took the initiative to organise continuing education seminars for GPs on the prevention of suicide.

The authors would like to express their gratitude to the Sentinel General Practitioners and to the Etablissement Public Régional d'Aquitaine.

Address for correspondence and reprints: Sylvie Maurice, Laboratoire d'Epidémiologie, Biostatistiques et Informatique Médicale, Université de Bordeaux 2, 146 rue Léo-Saignat, 33076 Bordeaux Cedex, France.

\section{References}

${ }^{1}$ Langmuir AD. William Farr: Founder of modern concepts of surveillance. Int J Epidemiol 1976; 5: 13-8.

2 Maurice S, Salamon R, Dabis F. Surveillance épidémiologique: Expérience en Aquitaine d'un réseau de médecins sentinelles. Rev Epidemiol Sante Publique 1988; 36: 494-5.

${ }^{3}$ Valleron AJ, Bouvet E, Garnerin P, et al. A computer network for the surveillance of communicable diseases: The French experiment. Am J Public Health 1986; 76: 1289-92.

${ }^{4}$ Pommereau X, Penouil F. Suicidal women and their intimate conflicts with men. In: Proceedings of the AAS/IASP Meeting, San Francisco, May 1987. American Association of Suicidology, 1987.

${ }^{5}$ Davidson F, Philippe A. Suicide et tentatives de suicide aujourd'hui: Etude épidémiologique. Paris: INSERM/ Doin Ed, 1986.

${ }^{6}$ Pommereau X, Penouil F. Parasuicide by jumping: a 5-year study. In: Second European Symposium on Suicide Behaviour, Edinburgh, May 1988. Edinburgh: Edinburgh University Press (in press).

${ }^{7}$ Monk M. Epidemiology of suicide. Epidemiol Rev 1987; 9: 51-69.

8 Boor M. Methods of suicide and implications for suicide prevention. J Clin Psychol 1981; 37: 70-5.

${ }^{9}$ Farmer RDT. The relationship between suicide and parasuicide. In: Farmer R, Hirsch S, Eds. The suicide syndrome. London: Croom Helm, 1980: 19-37.

${ }^{10}$ Farmer R, Rohde J. Effect of availability and acceptability of lethal weapons on suicide mortality: an analysis of some international data. Acta Psychiatr Scand 1984; 62: 436-66.

${ }^{11}$ National Center for Health Statistics: Vital Statistics of the United States, 1950, vol 3. Mortality data. Washington, DC: DHEW, Public Health Service. 1953.

12 National Center for Health Statistics. Vital statistics of the United States, 1980, vol 2. Mortality, Part A. Washington, DC: DHHS, Public Health Service, 1984.

${ }^{13}$ Lester D, Murrell ME. The influence of gun control laws on suicidal behaviour. Am J Psychiatry 1980; 137: 121-2.

14 Lester D, Murrell ME. The preventive effect of strict gun control laws on suicide and homicide. Suicide Life Threat Behav 1982; 12: 131-40.

15 Medoff MH, Magaddino JP. Suicide and firearm control laws. Evaluation Review 1983; 7: 357, 372.

16 Markush RE, Bartolucci AA. Firearms and suicide in the United States. Am J Public Health 1984; 74: 123-7.

Accepted for publication February 1989 